\title{
Amálgama dental e seu papel na Odontologia atual
}

\section{Dental amalgam and its role in current dentistry}

\section{Danielle Tiburcio Santos}

Aluna de Mestrado Profissional em Clínica Odontológica da FO/UFRJ

Katia Regina Hostilio Cervantes Dias

Professora Doutora de Mestrado Profissional em Clínica Odontológica da FO/UFRJ

Márcia P. Alves dos Santos

Professora Doutora Colaboradora de Mestrado Profissional em Clínica Odontológica da FO/UFRJ

\section{Resumo}

O Amálgama de Prata (AP) é um material restaurador consagrado pelo uso na Odontologia. Embora nos últimos anos tenha havido uma procura maior pelas restaurações estéticas, ao se considerar aspectos inerentes à eficácia, eficiência, custo e efetividade, particularmente em Saúde Pública, 0 $\mathrm{AP}$, quando indicado, permanece como material de eleição para restaurações posteriores intracoronárias. Há uma tendência mundial de banir o uso do $\mathrm{AP}$ devido à toxicidade do mercúrio para 0 ambiente e para a saúde humana, mas não existem evidências científicas sobre isto. De concreto, há necessidade de realizar o gerenciamento de resíduos químicos de AP. Sendo assim, o objetivo deste estudo é revisar na literatura sobre o gerenciamento de resíduos do $\mathrm{AP}$ e colaborar nesta orientação, propondo um guia.

Palavras-chave: amálgama dentário; meio ambiente; resíduos odontológicos; gestão de resíduos; protocolos.

\section{Abstract}

The Silver Amalgam (SA) is a restorative material established by custom in dentistry. Although in recent years there has been a greater demand for esthetic restorations, when considering issues related to the effectiveness, efficiency, cost-effectiveness, particularly in Public Health, the SA, when indicated, remains the material of choice for intra-coronary posterior restorations. There is a global trend to ban the use of SA due to the toxicity of mercury to the environment and to human health, but have no scientific evidence of this. Specifically, there is need for the management of chemical waste SA. Thus, the aim of this study is to review the literature on the SA waste management and collaborate in this direction by proposing a guide.

Keywords: dental amalgam; environment; dental waste; waste management; protocols.

\section{Introdução}

O Amálgama de Prata (AP) é um material restaurador secular consagrado pelo uso na Odontologia, com fortes evidências científicas de sucesso clínico. Embora nos últimos anos tenha havido uma procura crescente por restaurações estéticas, ao se considerar aspectos inerentes sua eficácia e segurança, particularmente na perspectiva da Saúde Pública, o AP, quando indicado, permanece como material de eleição para restaurações intracoronárias em dentes posteriores. Ademais, em 2009, a Organização Mundial da Saúde (OMS) concluiu que os materiais restauradores existentes não substituíam adequadamente o AP.

O AP resulta da mistura de mercúrio, prata, estanho e cobre, podendo conter também índio, zinco, platina e/ou paládio, dependendo do fabricante $(1,2,3)$. Nos últimos anos, há uma grande discussão em relação à continuidade de uso do AP na prática clínica odontológica $(4,5)$, dada a presença de mercúrio, um metal pesado extremamente tóxico. Tal fato se baseia, principalmente, no risco em potencial do AP contaminar o meio ambiente, devido ao seu uso e descarte inadequados (6).

As restaurações de AP foram banidas em alguns países, como Noruega, Dinamarca e Suécia, devido ao ocorrido no "Desastre de Minamata", onde mais de 1400 pessoas morreram em consequência direta da intoxicação por mercúrio. No entanto, é fundamental esclarecer que naquela época, Minamata, uma cidade localizada no Japão, era uma região de pesca, as pessoas viviam desta atividade e consumiam peixes regularmente. Com o passar do tempo, muitas pessoas começaram a ter perda de visão, descoordenação motora e muscular. Mais tarde, descobriu-se que as deficiências eram causadas pela destruição dos tecidos do cérebro, em razão da contaminação por mercúrio. No entanto, não se sabia de que maneira a contaminação havia ocorrido. Após três anos do incidente, as autoridades japonesas descobriram que uma indústria local utilizava um composto de mercúrio que, ao atingir a Baía de Minamata, incorporava-se à cadeia alimentar dos peixes. Os compostos orgânicos presentes na carne dos peixes causavam doenças às pessoas que a consumiam (5). Em 2007, o Programa das Nações Unidas para o Meio Ambiente (UNEP - United Nations Environment Programme) formalizou a Parceria Global do Mercúrio para minimizar ou eliminar o uso do mercúrio. Alguns países baniram o AP sob a argumentação da sua toxicidade, no entanto, tal capacidade ainda precisa ser comprovada cientificamente.

No Brasil, o AP é amplamente usado devido a sua eficácia, eficiência, custo e benefício. Banir o seu uso, geraria um impacto negativo significativo para a saúde (bucal) das pessoas.

A Convenção de Minamata ocorrida em 2013, dentre outros encaminhamentos, produziu um documento para promover a redução, controle e eliminação de produtos que contenham Mercúrio. Mais de 140 países, entre eles o Brasil, são signatários deste acordo, que entrou em vigor em 2013. Muitos produtos deverão ser banidos até 2020 como, por exemplo, termômetros, lâmpadas, pilhas e baterias que possuem mercúrio em sua composição. Entretanto, para o AP, o documento prevê a diminuição gradativa no uso do produto, sem determinar um prazo para que isso ocorra (7).

No sentido de acatar a recomendação da Convenção de Minamata e ainda contemplar questões peculiares ao uso do AP, como material restaurador no 
Brasil, promover o melhor gerenciamento do descarte dos resíduos do AP seria oportuno, pois reduziria a agressão ao meio ambiente e à saúde humana. Um estudo mostrou que existem clínicas odontológicas que fazem o descarte de resíduos de amálgama no sistema de descarte de lixo comum (4), o que contraria as normas da vigilância sanitária (8). Ao ser descartado entre os resíduos comuns, o mercúrio, presente nos resíduos de amálgama, inevitavelmente, atingirá os compartimentos ambientais como rios, lagos ou o solo úmido, e sofrerá biotransformação em mercúrio orgânico, altamente tóxico, por organismos aquáticos. Esta substância, em níveis baixos, causa danos ao sistema nervoso, tem alta persistência e se acumula em animais, peixes e no meio ambiente global (5). Os animais, ao ingerirem alimentos contaminados com mercúrio, ficam intoxicados e, ao se prestarem a alimentos para os humanos, favorecem o desenvolvimento de doenças crônicas, causando problemas cardíacos, respiratórios, neurológicos, entre outros. A contaminação pelo mercúrio pode ocorrer também pelas vias respiratórias e por contato cutâneo (9).

Segundo a Resolução no 306/04 da Agência Nacional de Vigilância Sanitária (ANVISA), o tratamento de resíduos de serviços de saúde consiste na aplicação de método, técnica ou processo que modifique as características dos riscos inerentes aos resíduos, reduzindo ou eliminando o risco de contaminação, de acidentes ocupacionais ou de dano ao meio ambiente (8).

Sendo assim, este trabalho tem como objetivo realizar uma revisão de literatura sobre o gerenciamento dos resíduos de AP e dar a contribuição no sentido de propor orientações para tal.

\section{Material e Métodos}

Esta pesquisa é de base secundária, tipo revisão de literatura narrativa, na qual foram associados os descritores "Amálgama Dentário", "Meio Ambiente", "Resíduos Odontológicos", "Gestão de Resíduos" e "Protocolos". A busca foi realizada no período entre março de 2014 e agosto de 2015, nos idiomas inglês e português, nas bases PubMed e Bireme. Além disso, utilizou-se busca manual nas referências dos artigos.

\section{Resultados}

Com base na pesquisa, segundo os autores consultados, constatou-se que o AP não oferece riscos significativos à saúde humana nem ao meio ambiente, desde que haja gerenciamento e descarte adequados de seus resíduos $(6,1,7$, $10,11,12)$.

\section{Discussão}

A ANVISA classifica os resíduos de AP como aqueles que contêm substâncias químicas que podem apresentar risco à saúde pública ou ao meio ambiente, dependendo de suas características de inflamabilidade, corrosividade, reatividade e toxicidade (5).

Porém, não existem estudos científicos suficientes que comprovem que o AP possa causar danos à saúde, se hou- ver um manejo adequado deste material (1). Em um estudo, SHERMAN et al. (13) comparam, através de biomarcadores, a quantidade de mercúrio na corrente sanguínea em pacientes com amálgama $(0,7 \mu \mathrm{g} / \mathrm{ml})$, pacientes sem amálgama $(0,3 \mu \mathrm{g} / \mathrm{ml})$ e realizando 1 refeição por semana contendo alimentos marinhos $(2,3$ a $5,1 \mu \mathrm{g} / \mathrm{ml})$. Isso mostra que o maior risco de contaminação do mercúrio para a saúde provém do consumo de peixes e não do AP (1).

De acordo com dados da UNEP, a Odontologia tem uma pequena participação no total de emissões de mercúrio derivadas de atividades humanas, que seria proveniente da liberação de vapor pelas restaurações de amálgama durante a cremação, contribuindo com menos de $1 \%$ do total gerado, em âmbito mundial. Setenta por cento das emissões de mercúrio produzidas vêm de usinas de energia abastecidas com carvão (10). O mercúrio também é liberado naturalmente por rochas, pelo solo e por erupções vulcânicas. Poucos estudos objetivaram estimar a liberação de mercúrio no meio ambiente por meio do descarte de resíduos de AP. No âmbito global, a contaminação advinda do setor pode variar de 3 a 4\% da emissão industrial e da queima de combustíveis fósseis $(5,1)$.

Havendo o gerenciamento e descarte adequados destes resíduos, o AP não gera prejuízo significativo à saúde e ao meio ambiente (1), porém resíduos de AP gerados em consultórios odontológicos, centros de saúde e outras unidades correlatas podem gerar contaminação ambiental quando são dispostos impropriamente no lixo, ou se descartados nos sistemas de esgoto que servem esses locais $(5,14)$. O ambiente contaminado dos consultórios constitui risco não só para os profissionais como também para os pacientes, principalmente aqueles submetidos a procedimentos demorados ou os que necessitam de retornos constantes (5).

Alguns centros de pesquisa vêm estudando soluções para o descarte de resíduos de AP, tais como o Instituto de química da UNICAMP e a USP/Bauru (4), porém, o que se observa, em muitas instituições no país, é que o correto gerenciamento de resíduos não vem sendo praticado. Isto se deve, em parte, ao desconhecimento a respeito da legislação sobre o descarte, tanto nas universidades quanto em empresas particulares, à ausência de programas de educação ambiental, a não prioridade institucional dada ao assunto e a falta de fiscalização dessas atividades por parte dos órgãos governamentais. Não há programas de treinamento dentro das instituições para os profissionais, até mesmo professores desconhecem esse assunto, acarretando, consequentemente, a não transmissão dessas informações para os alunos. Essa é uma das razões que mostram por que a Universidade, como disseminadora de conhecimento, não pode se ausentar da sua responsabilidade quanto aos resíduos gerados em suas dependências.

O gerador do resíduo passou a ser responsável pelo seu gerenciamento, até a disposição final do mesmo (15). As penalidades previstas para o manuseio inadequado incluem multa e prisão (7). 
A geração de resíduos é um grave problema para muitos países, uma vez que a quantidade requer espaço e tecnologias para recuperação e tratamento. Mesmo sendo pouco eficaz, em geral, tenta-se que este mercúrio seja coletado e reciclado para produzir novos produtos (5). O processo de recuperação dos resíduos do amálgama é feito através da remoção do mercúrio, adaptando-se a metodologia utilizada por PÉCORA (16).

O tratamento do resíduo dos amálgamas dentários deve ser realizado em uma instalação especial, controlada e licenciada para essa atividade, capaz de reter todo o mercúrio contido no amálgama (da ordem de $50 \%$ em peso). No processo de reciclagem do mercúrio em amálgamas dentários, faz-se a destilação do mercúrio através de retorta a vácuo (destilador de mercúrio), onde passarão pelo processo de desmercurização. Nesta etapa, os resíduos mercuriais são aquecidos a uma temperatura de, aproximadamente, $480 \mathrm{oC}$ e baixa pressão. O mercúrio destilado é extraído com cerca de $99,9 \%$ de pureza e os demais materiais saem do processo descontaminados. Esse tipo de instalação requer investimentos onerosos, não somente pelos equipamentos que contém, como também pelo controle das condições de saúde e segurança do trabalho de seus operadores $(5,17)$.

Embora exista tecnologia disponível para sua reciclagem, esta depende do interesse da indústria. Por isso, a solução aceitável, se a reciclagem não for possível, é o despejo em aterro sanitário industrial (15). O método exige supervisão e certa quantidade de manutenção. O mercúrio requer que o aterro esteja protegido contra intrusão, para evitar risco à saúde humana e ao meio ambiente. O mercúrio armazenado deve ser protegido contra a exposição direta à chuva, sol, vento, inundações, condições de frio extremo, escavação e construção. Isso cria algumas exigências sobre a instalação de armazenamento onde o mercúrio é mantido. Além disso, as condições geotécnicas e tectônicas no local devem ser cuidadosamente avaliadas para garantir a estabilidade física da instalação de armazenamento (3).

Como principal substituto ao AP, além de maior custo, a Resina Composta (RC) tem muitas limitações, tais como: a falta de evidências que comprovem que a RC seja um material inerte e sensibilidades técnica e operatória mais criteriosas, que demandam por maior tempo clínico. Acrescenta-se também maior chance de falhas, contração de polimerização e sorção de água, que podem levar à degradação marginal e cáries secundárias (1), com grande chance de envolvimento endodôntico. Menores resistência, dureza e durabilidade clínica.

Todos estes fatores têm impacto significativo negativo, ao se pensar em bases populacionais (1). Portanto, a utilização e o ensino do amálgama nas universidades ainda são pertinentes. $\mathrm{O}$ aluno que não aprende a fazer o correto descarte dos resíduos na universidade não o fará em sua vida profissional, seja no setor privado ou no setor público, sendo mais um contribuinte para o descarte inadequado destes resíduos no meio ambiente. Além disso, os que decidem ingressar na vida acadêmica se tornarão professores e não saberão ensinar aos seus futuros alunos o correto manejo e descarte dos resíduos odontológicos.

Além disso, deve ser de responsabilidade dos departamentos que atuam em clínica odontológica o conhecimento do descarte de seus respectivos resíduos na universidade. Se a própria universidade não fizer a coleta e manejo dos resíduos, deve haver o contrato de empresas particulares que os façam e deve haver constante acompanhamento, pelos departamentos, dos serviços executados por estes institutos ou empresas.

\section{Considerações finais}

Com base na literatura consultada, para o gerenciamento dos resíduos de AP alguns cuidados devem ser tomados, tais como:

1- Manipulação com mão enluvada, uso de máscara e de óculos;

2- Consultório dotado de alta exaustão;

3- Não utilizar condensadores automáticos;

4- Uso de alta sucção durante a remoção de uma restauração e utilizar brocas novas e água gelada para este procedimento;

5- Uso da menor relação possível de mercúrio na liga. Uma das soluções para minimizar a quantidade de mercúrio nos resíduos de amálgama seria utilizar ligas esféricas com alto teor de cobre, que requerem menor quantidade de mercúrio para a confecção de um amálgama dentário de qualidade;

6- Uso de isolamento absoluto para evitar queda de amálgama na cavidade bucal, levando-se em consideração que a mucosa do assoalho da cavidade bucal é altamente permeável;

7- Mercúrio, amálgama ou qualquer equipamento usado com amálgama nunca devem ser aquecidos;

8- O uso de soluções desinfetantes à base de mercúrio deve ser eliminado;

9- As clínicas e os locais de manuseio devem ser bem ventilados;

10- O mercúrio deve ser armazenado em recipientes fechados e inquebráveis longe de qualquer fonte de calor, sob selo d'água e com rótulo padronizado com o símbolo de substância tóxica, acrescidos da expressão: "RESÍDUO QUÍMICO";

11- A remoção do excesso de mercúrio antes da condensação deve ser evitada;

12- Amalgamadores com redoma de proteção devem ser usados;

13- Jatos de água e sugadores de alto volume devem ser usados quando se remove restaurações de amálgama ou durante o polimento/acabamento de restaurações novas;

14- A pele acidentalmente contaminada pelo mercúrio deve ser lavada cuidadosamente com água e sabão; 
15- A utilização de ar condicionado deve ser sempre na posição de renovação do ar;

16- O uso de condensadores ultrassônicos de amálgama deve ser evitado;

17- Uso de amalgamadores mecânicos seguros, que não apresentem vazamentos de mercúrio. $\mathrm{O}$ amalgamador deve ficar guardado em local isento de calor, longe do Forno de Pasteur, Autoclave e distante do aparelho de ar condicionado, para evitar a formação e dissipação dos vapores de mercúrio. Cuidados especiais deverão ser tomados no momento de usar o amalgamador, evitando acidentes;

18- A cápsula deve ser rosqueada, substituída de tempo em tempo para evitar escapamento de mercúrio. A sua fixação deve ser perfeita;

19- No caso de suspeita de vazamento pode ser colocada uma fita adesiva envolvendo a cápsula. Após trituramento, deve-se observar se há vestígios de mercúrio na fita. Remove-se a cápsula após a parada completa do motor;

20- O resíduo de amálgama deve estar isento de algodões, gazes, palitos, lâminas de matriz de aço e quaisquer outros tipos de contaminante;

21- Os frascos que contém o mercúrio, bem como a tampa, devem ser enviados para o laboratório de reciclagem;

22- Qualquer material descartável contaminado com mer- cúrio ou amálgama deve ser colocado em saco selado de polietileno;

23- As cápsulas devem ser estocadas e encaminhadas para recuperação;

24- Os recipientes específicos para descarte de material não devem ser preenchidos acima do limite de $2 / 3$ de sua capacidade total e devem estar localizados sempre próximos do local onde é realizado o procedimento.

\section{Conclusão}

O maior problema do uso do amálgama está relacionado à necessidade de implementar melhorias no sistema de descarte dos seus resíduos, logo se faz necessária a divulgação de orientações sobre o descarte de resíduos de amálgama, com foco no impacto das práticas odontológicas sobre o meio ambiente e sobre a saúde humana, para fomentar o desenvolvimento de políticas na aplicação de estratégias que diminuam sua contaminação. Paralelamente, a Prevenção da Cárie Dental deveria ser considerada um paradigma a ser alcançado, no sentido de reduzir número de dentes a serem restaurados. Deve-se, também, desenvolver novos materiais restauradores, que possam ser indicados como alternativos ao AP e ao alcance de toda a população.

Em comum a todas as ações citadas, está a necessidade de educação permanente para os atuais e futuros profissionais da Odontologia. 


\section{Referências ::}

1- Mondelli J. O que o cirurgião-dentista que prática a Odontologia deve saber a respeito do amálgama dentário. Full Dent. Sci. 2014;5(19):511-26.

2- Pécora JD. Guia prático sobre resíduos de amálgama odontológico. Projeto FAPESP. 2003;01/01065-1.

3- Höglund LO. Technical options for storage and disposal of Mercury.

4- Pereira MA. Gestão e Tecnologias para o Reaproveitamento de Resíduos e Efluentes de Clínicas Odontológicas: Análise da Experiência da Faculdade de Odontologia de Bauru (FOB/USP) e Proposta para a Faculdade de Odontologia de Lins (FOL/UNIMEP). Santa bárbara d'oeste: UNIMEP; 2004. 208p. Mestrado.

5- Agência Nacional de Vigilância Sanitária. Gerenciamento dos Resíduos de Mercúrio nos Serviços de Saúde. Brasília: Ministério do Meio Ambiente; 2010.

6- Narvai PC. O mercúrio não é vilão. Jornal Odonto. 2014.

7-Anais Simpósio Amálgama Dental. 2014. São Paulo. Brasil. 2014. 8p.

8- Agência Nacional de Vigilância Sanitária. Regulamento Técnico para o Gerenciamento de Resíduos de Serviços de Saúde. Brasília, DF: Diário Oficial da República Federativa do Brasil, Poder Executivo; 2004.

9- Barbin EL, Spanó JCE, Pécora JD. (Faculdade de Odontologia - USP). Guia prático sobre resíduos de amálgama odontológico. Laboratório de Gerenciamento de Resíduos Odontológicos. Ribeirão Preto: Projeto FAPESP 01/01065-1; 2003.

10- Elizaur Benitez ABC, Fuller JB, Salgado PE, et al. Amalgama dental: estudo "in vitro" da liberação de mercúrio, através de espectrofotometria de absorção atômica, em função do tipo de ligas, polimento e tempo. Rev. Odontol. Univ. São Paulo. 1995;9(1):39-43.

11- Kropp R, Hausselt JH. A liberação de mercúrio dos amálgamas dentais em água em comparação com a absorção de mercúrio pelas pessoas através alimentação normal. Die quintessenz. 1993;6493:1-5.

12- Anais Simpósio GBPD 2015: Continuar ensinando amálgama? Belém, Pará. Brasil. 2015.

13- Sherman LS, Blum JD, Franzblau A, et al. New insight into biomarkers of human mercury exposure using naturally occurring mercury stable isotopes. Environ Sci Technol. 2013;47(7):3403-9.

14- Mota SM, et al. Impacto dos resíduos de serviços de saúde sobre o homem e o meio ambiente. Arquivos em Odontologia. 2004;40(2):111-206.

15- Protocolos de biossegurança para profissionais em odontologia. SESI/ DR/AC. Rio Branco-AC: 2009.

16- Pécora JD, Silva RGS, Souza RA, et al. Reciclaje de los resíduos de amalgama dental mediante la recuperatión de mercúrio y plata. Rev. FOLA. 1998;4(14):234-7.

17- Apliquim Brasil Recicle. Processamento de Amálgamas e Resíduos Mercuriais [http://www.apliquimbrasilrecicle.com.br/servicos/3/processamento-de-amalgamas-e-residuos-mercuriais]. Porto Alegre; 2015.

Recebido em: 24/08/2015 / Aprovado em: 28/09/2015

Danielle Tiburcio Santos

Rua São Marcos, 24 - Saracuruna

Duque de Caxias/RJ, Brasil - CEP 25220-160

E-mail: danielletib@gmail.com 